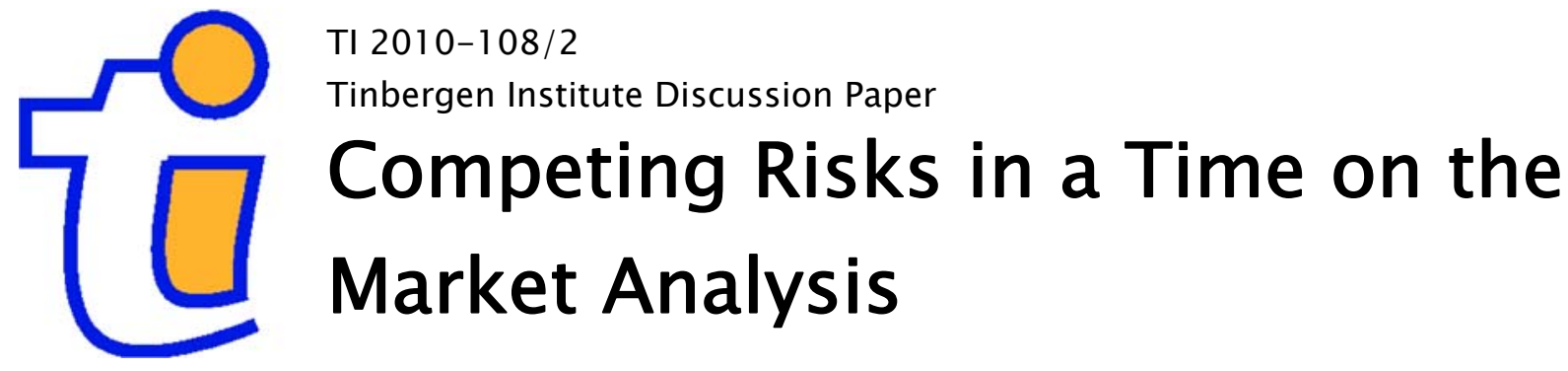

Erik R. de Wit

Finance Group, University of Amsterdam, Tinbergen Institute. 


\section{Tinbergen Institute}

The Tinbergen Institute is the institute for economic research of the Erasmus Universiteit Rotterdam, Universiteit van Amsterdam, and Vrije Universiteit Amsterdam.

Tinbergen Institute Amsterdam

Roetersstraat 31

1018 WB Amsterdam

The Netherlands

Tel.: +31(0)205513500

Fax: $+31(0) 205513555$

Tinbergen Institute Rotterdam

Burg. Oudlaan 50

3062 PA Rotterdam

The Netherlands

Tel.: + $31(0) 104088900$

Fax: $+31(0) 104089031$

Most TI discussion papers can be downloaded at http://www.tinbergen.nl. 


\title{
Competing Risks in a Time on the Market Analysis
}

\author{
Erik R. de Wit*
}

October 2010

\begin{abstract}
Theoretical models on the selling process in the housing market are scarce. Taylor (1999) specifies a model where time-on-the-market gives a quality signal of the house to potential buyers if inspection outcomes of the house are not public. We specify a duration model with competing risks, where the competing risks are a sale or a withdrawal from the market. We use a unique administrative dataset from the Netherlands. We find negative duration dependence in the hazard of sale and positive duration dependence in the hazard of withdrawal confirming the empirical predictions from Taylor (1999).
\end{abstract}

${ }^{*}$ Finance Group - University of Amsterdam, Tinbergen Institute.

E-mail: erikrdewit@gmail.com

Erik R. de Wit is grateful to the Amsterdam School of Real Estate and the NVM (Dutch Association of Real Estate Brokers and Real Estate Experts) for providing the data. 


\section{Introduction}

When a home owner puts her house up for sale she will set her reservation price for the asset in such a way that the expected utility of the state of the world wherein she owns the house equates to the expected utility of the state of the world wherein she does not own the house. Not owning the house might mean selling the house and moving to another city with better job prospects. Not owning can also mean moving to another type of house or neighborhood which better matches her current needs. Not owning might also mean accepting a price for the house above the present value of a stream of future rental income. The key point is that a home owner will only participate in trade if it increases her expected utility.

Home owners who have put their house up for sale might withdraw their house from the market if the alternative state of the world to owning the house has ceased to exist (e.g. the job offer in the other city has been withdrawn or the groom ran away from the alter). Such events can reasonably be assumed to be exogenous to the selling process of the house. In fact, if the housing market were a perfectly competitive market (as in e.g. Olsen 1969), such events would be the only cause for a home owner to withdraw a house from the market. However, housing markets are characterized by asymmetric information between the seller and potential buyers (and even among potential buyers).

Taylor (1999) formulates a theoretical model in which buyers herd if the outcome of quality inspections of the house are not observed to potential buyers. The result is that the mean valuation of a house from potential buyers decreases the longer the house has been for sale on the market. At some point home owners are more likely to prefer a withdrawal of their house from the market and retain the utility their house currently brings them

over seeing their house becoming even more stigmatized. Keeping the house for sale on the market any longer would result in the mean valuation from potential buyers falling even further below her reservation price the longer the house remains on the market.

Thus, the theory describes a positive relation between the time a house has been for sale on the market and the rate at which home owners withdraw 
their house from the market. This paper tests this hypothesis empirically. We find a strong relation between time on the market and the rate at which houses are withdrawn from the market. For example, the rate at which houses are withdrawn from the market is $140 \%$ higher between 181 and 270 days on the market compared to the first 30 days on the market.

We use a mixed proportional hazard model with competing risks. The empirical model builds on Heckman and Honoré (1989). The competing risks are an exit of the house from the market through either a sale or a withdrawal from the market. We use a piecewise constant specification for the duration dependence in the transition rates from market to sale and market to withdrawal. Moreover, we allow the duration dependence to be time-varying over the sample horizon.

We use a unique administrative data set from the NVM (Dutch Association of Real Estate Brokers and Real Estate Experts) on 1,820,022 houses put up for sale on the Dutch housing market during the period 1985-2007. The data contain daily information on the time the house was on the market. Also the reason for leaving the market is recorded, so we observe whether a house has been sold or withdrawn from the market by the seller. Furthermore, we observe a very extensive set of characteristics of each house.

The remainder of the paper is organized as follows. Section 2 describes the institutional setting of the Dutch market for owner occupied homes. Section 3 describes our empirical model that is inspired by the theoretical literature. Section 4 describes the unique administrative data set. Section 5 presents the estimation results and some sensitivity analyses. Section 6 concludes. 


\section{Institutional Setting of the Dutch Housing Market}

In this section we describe some institutional aspects of the Dutch housing market, whereby we focus on the owner occupied sector. It is not our intention to give an exhaustive description of the Dutch housing market. Instead, we explain the basic structure and highlight aspects that are relevant for our purposes. We rely on figures from Statistics Netherlands. The Netherlands had about 16 million inhabitants in 7 million households in 2006. Of these 7 million households, $56 \%$ live in an owner occupied house and the remaining part rent their house. The average sales price of existing owner occupied homes was 235,842 euro in 2006, which is 4.57 times the average income per household.

The Dutch housing market experienced a large real price increase during the 1990's. This price increase can be explained by several other factors apart from growth in real income. First, the Netherlands has an increasing population and one of the highest population densities in the world. Stringent spatial planning policy and very long planning procedures governing new residential construction make it more and more difficult to increase the housing supply. So, the increasing population will put upward pressure on house prices. Swank, Kakes and Tieman (2002), and Vermeulen and Rouwendal (2007) show that the Netherlands has an enormously low price elasticity of supply. Second, there were major changes in the Dutch mortgage finance market during the 1990's. Since 1990 banks can give a mortgage based on two salaries, taking the salary of the spouse into account (before 1990 banks could only give mortgages based on one salary). This has increased the budget for house buyers. Another major change was the enormous financial innovation in the mortgage market. New mortgage products were introduced during the 1990's such as the investment mortgage, which made it more affordable for many people to purchase a house. This all happened in an environment of falling mortgage rates (e.g. the 5-year fixed mortgage rate fell from $9.3 \%$ in January 1990 to $3.8 \%$ in January 2006) and stable inflation of about 2\% per year.

The Dutch owner occupied housing market is highly subsidized through 
the mortgage finance market. Home owners can subtract the interest costs on their mortgage from their taxable income at the marginal income tax rate. This leads to a reduction in interest costs of $32-52 \%$. Home owners do have to pay an imputed rent tax but this tax is very small. The tax savings make owning a house very popular among mid to high income citizens in the Netherlands. In a survey OTB (2003), over 90\% of respondents indicated they preferred purchasing a house over renting if they could afford to purchase a house. Housing is now the largest asset class on the household balance sheet with $54 \%$ of total household assets, pension assets come second with $44 \%$ of total assets. These numbers were respectively, $43 \%$ for housing and $28 \%$ for pensions in 1980. Van Ewijk and ter Rele (2008) mention that this trend has made Dutch households more vulnerable to shocks in national and international housing markets and financial markets.

The Netherlands has one of the most highly developed mortgage markets in Europe. Financial institutions offer a wide variety of mortgages. The Gedragscode Hypothecaire Financieringen (code of conduct for mortgage finance) describes among other things the maximum loan-to-income ratios mortgagees can obtain. For most Dutch citizen, 4.5 times the income is the maximum they can borrow but this also depends on interest rates and banks can provide higher loans in exceptional cases. The code of conduct does not give guidelines on the maximal loan-to-value ratio. The average loan-to-value ratio for first-time buyers in 2007 was 114\% (Ball 2009). Of owner-occupiers, $89 \%$ have a mortgage. House owners can insure their mortage against default through a national insurance scheme known as Nationale Hypotheek Garantie (NHG). This insurance will cost the borrower 30 basis points of the principal of their loan but will give them a 20-30 basis point reduction on their interest rate. In case the borrower defaults the NHG scheme will pay the debt service to the bank and the NHG will try to recoup the principal and interest from the borrower if possible.

There are substantial transaction costs involved in purchasing a house in the Netherlands. The total transaction costs on the purchase of an existing home is approximately $10 \%$. The cost components are transaction tax $(6 \%$ of sales price), broker costs (1-3\% of sales price), mortgage initiation fees (1-1.5\% of mortgage principal), notary fees and possibly intermediary fees. 
These transaction costs are typically financed by including them in the mortgage principal. Stamp duty does not have to be paid on new houses but a 19\% VAT applies.

The seller of the house usually uses the services of a real estate broker. About $70 \%$ of all houses offered for sale are offered through a member of the NVM. The real estate broker will advise the seller on a suitable list price, but it is the seller who will decide on the list price. The real estate broker will advertise the house in media such as local newspapers and more recently the internet. Advertisements normally contain the list price, pictures of the house, and a description on the characteristics. Over the last ten years the internet has become an important medium for advertising houses offered for sale. The real estate broker only receives a fee if the house is actually sold and the fee is usually $1-3 \%$ of the transaction price. Interested potential buyers will contact the broker for information requests and to schedule visits. The broker will usually host a visit to the house and the seller will not be present.

List prices do not have a formal role in the Netherlands since they are not binding. A seller can try to refuse a list price or try to negotiate a higher price even if a potential buyer is willing to pay the list price. There are rules to the negotiation process between buyer and seller. A potential buyer will communicate his bid to the broker. The broker will inform the seller of the bid and this starts the negotiation process. Negotiation with several buyers at the same time or revealing bids to other buyers is not allowed. The order in which the seller should negotiate with potential buyers is based on the order in which the potential buyers make their first bid. The seller has by law an obligation to reveal all relevant information about the house. The buyer can hold the seller liable if he discovers a hidden defect to the house which had originated before the purchase date. The buyer would of course have to proof that the defect actually originated before the purchase in case the seller claims otherwise.

The rental market in the Netherlands consists of roughly $44 \%$ of the total market; roughly $90 \%$ of which is regulated. The rental market is strongly regulated through a system that prescribes both the rent level and the maximum annual rent increase. Furthermore, the dominant position of housing associations (jointly owning $75 \%$ of the total rental stock) has large implication 
on the rental sector. In general, housing associations set rents well below the maximum level allowed for by law, thus further increasing benefits to rental households. Partly because of the dominant position of housing associations the private rental sector is almost non-existent in the Netherlands.

The mentioned subsidization schemes influence tenure choice in the Netherlands. Conijn and Schilder (2009) show that there is a strong positive relationship between the probability of a household being owners and the income of the household. Of all renters, $31 \%$ receive rent subsidy. Rent subsidy is available for low income households, so renting is more attractive for low income households. Moreover, access to most housing of housing associations is restricted to income, higher income groups being unable to obtain such housing. On the other hand, since the Netherlands has a progressive income tax scale and mortgage interest costs are 100\% deductible, owning becomes progressively more attractive the higher the income of the household. Koning, Saitua and Ebregt (2006) and Romijn and Besseling (2008) estimate the total amount of subsidies in both sectors (including tax deductibility, rent subsidy and implicit subsidies following rent regulation) to be approximately balanced for owner-occupier and renter households; the total amount of subsidization is roughly 14.25 billion euro annually in the owner-occupied sector and approximately 14.5 billion euro annually in the rental sector.

\section{The Model}

\subsection{Theoretical Framework}

If the housing market were a perfectly competitive market (as in e.g. Olsen 1969) with symmetric information, only exogenous events would cause withdrawals of houses from the market. Caplin and Leahy (1996) discuss the importance of trading costs, price, and volume in assets markets with frictions. The authors focus among other things on the importance of self-selection effects in which the volume of trade reveals information not only on those who actually complete trades, but also on those who choose not to trade. Here low volume means that many agents posses information that has convinced them that trade is not profitable. The implication of this is that withdrawals 
of houses from the market might not be exogenous events.

Taylor (1999) analyses time-on-the-market as a sign of quality in a twoperiod model with two-sided asymmetric information and learning by potential buyers. The analysis focus on how potential buyers view time-on-themarket as a quality signal of the house. A potential buyer who discovers a house which has been for sale for a long time will naturally be suspicious about the reason the house did not sell earlier. Three possible reasons are presented, i) she may be the first potential buyer to discover the house, ii) the house may have been overpriced given the preferences of earlier potential buyers, or iii) earlier potential buyers might have detected a flaw in the house which is not apparent to her. The weight the potential buyer assigns to either possibility i or ii being the case will decline with time-on-the-market as the number of potential buyers who will consider the house increases with time. This means the weight assigned to possibility iii increases with timeon-the-market. The result is that the expected sale price and probability of a sale will decline with time-on-the-market if quality inspections are not made public. This herding and informational cascade effect will not occur if inspections are public and reservation price histories are observable. Herding creates two opposing incentives for the seller if historical reservation prices are observable (and inspections unobservable). First, relatively lower expected sale prices at longer market times gives the seller an incentive to set a lower initial reservation price in order to sell at a shorter market time with a higher sale probability (the option-value effect). Second, the seller has an incentive to set a high initial reservation price so that potential buyers who discover the house after a longer market time will believe that failure to sell at a shorter market time was due to a lack of a serious buyer rather than detection of low quality (the signal-dampening effect). The herding effect will be increased if the reservation price history is not observable. In this setting there still is an option-value effect but no signal-dampening effect. The model is specified with high and low quality houses where low quality sellers will mimic the reservation prices of high quality sellers. In this setting sellers cannot use the reservation price as a signal of quality. Houses that remain on the market for a long time become stigmatized, and can eventually be removed from the market as sale becomes unlikely. Empirical evidence con- 
firms that the probability of a sale decreases with time-on-the-market (e.g. Anglin, Rutherford and Springer 2003; Huang and Palmquist 2001; Pryce and Gibb 2006; and Zuehlke, 1987).

It must be noted that withdrawing the house from the market is not exogenous to selling it. The price a seller pays for keeping a house on the market too long is that both the probability of a sale and the potential buyer's mean valuation of the house will decline further the longer the house remains on the market. At some point home owners are more likely to prefer a withdrawal of their house from the market and retain the utility their house currently brings them over seeing their house becoming even more stigmatized ${ }^{1}$. Sellers of stigmatized houses with hidden flaws are more likely to reduce their reservation price while sellers of stigmatized houses without hidden flaws are more likely to withdraw. This also implies that the probability of a withdrawal should increase with time-on-the-market. Empirical analysis should therefore take withdrawals into account and consider that withdrawals might not be exogenous.

Coles and Smith (1998) develop a marketplace model. In this model there may not currently be a buyer who matches with the seller of a house. The seller will therefore have to wait till an appropriate buyer enters the market. This model differs from the search literature where a buyer-seller match exists but the agent has to pay search costs to find his match. In the marketplace model, when the seller puts up his house for sale his offer will first be evaluated by the stock of all potential buyers on the market. Once the current stock of buyers has rejected his offer he can only be matched by the new flow of buyers entering the market. If buyers spend a significant amount of time on the market then the flow of new buyers will naturally be much smaller then the stock of buyers. Hence, there should be a sudden drop in the probability of sale after the seller's offering has been rejected by the current stock of buyers.

\footnotetext{
${ }^{1}$ Note that the seller can withdraw the house from the market and put it up for sale again after some time if a first sale attempt failed. The stigma will be eliminated if the new group of potential buyers do not know about the past failed sale attempt. However, even if the new group of potential buyers is aware of the previous withdrawal they do not know with certainty whether the withdrawal was due to a stigma effect or exogenous factors.
} 
The key conclusion is that the probability of sale will decline with timeon-the-market and the probability of withdrawal will increase with time-onthe-market if quality inspections are not public (Taylor 1999). It is important to distinguish between information known to the market and to the econometrician. For example, reductions in reservation prices might be observed by both buyers and sellers but not by the econometrician. Furthermore, there should be a sudden drop in the probability of sale after a house has spend a sufficient time on the market for the current stock of potential buyers to have evaluated the offering (Coles and Smith 1998).

\subsection{Empirical Model}

The main conclusion from the theoretical literature is that withdrawals from the market are not exogenous to the selling process (e.g. Caplin and Leahy 1996; and Taylor 1999). In particular, Taylor (1999) shows that both the probability of a sale and the expected sale price decreases with time-on-themarket if the result of quality inspections are not public information. This implies that the probability of a withdrawal will increase with time-on-themarket as owners of stigmatized houses will prefer a withdrawal at some point over accepting a bid below the reservation price or seeing the stigma becoming even worse. The key empirical problem is that withdrawals are not exogenous to sales. The cause of the endogeneity is that the speed at which houses are sold and the speed at which houses are withdrawn from the market are simultaneously determined since they both depend on the characteristics of the house and the seller. Therefore, we model the probability of sale and probability of withdrawal as endogenous variables. We use a competing risks model with duration dependence to estimate the causal effect of time-on-themarket on the probability of sale and the probability of withdrawal (Heckman and Honoré 1989).

There might be information observed to market participants but not to the econometrician. For example, reservation prices are not observed by potential buyers but reductions in reservation prices might be signalled to potential buyers through list price reductions (see e.g. de Wit and van der Klaauw 2010). We have the initial list price in our data set but not any 
possible reductions in the list price. The implication of this is that we will underestimate the stigma effect since we cannot control for any possible list price reductions. That is, the true decline in the probability of sale with time-on-the-market will be more severe than we estimate. Analogously, the true increase in the probability of withdrawal will be higher than we estimate.

Consider a house which is put on the market at (calender) date $\tau_{0}$. Our model is a continuous time duration model in which $t$ denotes the time a house is already on the market. Let $\theta_{s}$ denote the rate at which houses are sold, and $\theta_{w}$ the rate at which houses are withdrawn from the market. These transition rates can depend on the duration the house is already on the market $t$, calendar time $\tau_{0}+t$, observed characteristics $x$, some characteristics $v$ which are observed by the market but unobserved to the econometrician.

We denote the unobserved heterogeneity term $v$ in the rate of selling the house by $v_{s}$, and in the rate of withdrawing by $v_{w}$. These terms are allowed to be correlated to each other, but are assumed to be independent of $x$ and $\tau_{0}$. Since the variables in $x$ are mainly used as control variables, and we will not causally interpret their covariate effect, this is not a strong assumption. Conditional on $\tau_{0}, x$ and, $v_{s}$, the rate at which a house is sold after $t$ periods on the market follows a familiar mixed proportional hazard specification

$$
\theta_{s}\left(t \mid x, \tau_{0}, v_{s}\right)=\lambda_{s}(t) \psi_{s}\left(\tau_{0}+t\right) \exp \left(x^{\prime} \beta_{s}+v_{s}\right)
$$

And a similar specification is used for the rate at which houses are withdrawn from the market

$$
\theta_{w}\left(t \mid x, \tau_{0}, v_{w}\right)=\lambda_{w}(t) \psi_{w}\left(\tau_{0}+t\right) \exp \left(x^{\prime} \beta_{w}+v_{w}\right)
$$

In this specification $\psi_{s}\left(\tau_{0}+t\right)$ and $\psi_{w}\left(\tau_{0}+t\right)$ are genuine calendar time effects modeled by dummies for each quarter. The functions $\lambda_{s}(t)$ and $\lambda_{w}(t)$ represent duration dependence and are our key functions of interest. We use very flexible specifications for the duration dependence functions. We take $\lambda_{s}(t)$ and $\lambda_{w}(t)$ to have a piecewise constant specification,

$$
\lambda_{i}(t)=\exp \left(\sum_{j=1,2, \ldots} \lambda_{i j} I_{j}(t)\right) \quad i=s, w
$$


where $j$ is a subscript for duration intervals, and $I_{j}(t)$ are time-varying dummy variables that are one in consecutive time intervals. A large number of intervals would allow any duration dependence pattern to be approximated arbitrarily closely. We normalize the pattern of duration dependence by fixing $\lambda_{i 1}=0$. Note that the duration dependence effect is controlled for calendar time effects (e.g. Pryce and Gibb 2006). This is especially important in our case since our database covers such a long time period. It should be noted that in a housing market with symmetric information, time on the market does not provide a signal to the market and the duration dependence terms should be constant. Our test for the absence of a herding effect thus consists of testing if $\lambda_{s}(t) \geq \lambda_{s}(t-h)$ and $\lambda_{w}(t) \leq \lambda_{w}(t-h)$, where $h \in(0, t]$. There might be a sudden sharp drop in the probability of sale after the house has spend a sufficient amount of time on the market for the current stock of potential buyers to have evaluated the offered house in line with the marketplace model (Coles and Smith 1998). However, the duration dependence terms should be constant after that initial drop if there is symmetric information in the housing market.

Let $t_{s}$ be the realized duration when a house is sold. The conditional density function of $t_{s} \mid x, \tau_{0}, v_{s}, v_{w}$ can be written as

$f_{s}\left(t_{s} \mid x, \tau_{0}, v_{s}, v_{w}\right)=\theta_{s}\left(t_{s} \mid x, \tau_{0}, v_{s}\right) \exp \left(-\int_{0}^{t_{s}} \theta_{s}\left(z \mid x, \tau_{0}, v_{s}\right)+\theta_{s}\left(z \mid x, \tau_{0}, v_{w}\right) d z\right)$

And similarly the conditional density function of the time until leaving the market $t_{l} \mid x, \tau_{0}, v_{s}, v_{w}$ equals

$f_{w}\left(t_{w} \mid x, \tau_{0}, v_{s}, v_{w}\right)=\theta_{s}\left(t_{w} \mid x, \tau_{0}, v_{w}\right) \exp \left(-\int_{0}^{t_{w}} \theta_{s}\left(z \mid x, \tau_{0}, v_{s}\right)+\theta_{s}\left(z \mid x, \tau_{0}, v_{w}\right) d z\right)$

Let $G\left(v_{s}, v_{w}\right)$ be the joint distribution function of the unobserved characteristics $\left(v_{s}, v_{w}\right)$. The joint density function of $\left(t_{s}, t_{w}\right)$ conditional on $x$ equals

$$
f_{s, w}\left(t_{s}, t_{w} \mid x, \tau_{0}\right)=\int_{v_{s}} \int_{0}^{v_{w}} f_{s}\left(t_{s} \mid x, \tau_{0}, v_{s}\right) f_{w}\left(t_{w} \mid x, \tau_{0}, v_{w}\right) d G\left(v_{s}, v_{w}\right)
$$

We use a very flexible specification for the joint distribution function of the unobserved characteristics $G\left(v_{s}, v_{w}\right)$ (e.g. Heckman and Singer 1984). We 
take the joint distribution of the unobserved heterogeneity terms $v_{s}$ and $v_{w}$ to be trivariate discrete with unrestricted mass-point locations for each term. Specifically, we allow for $K=3$ terms

$$
\operatorname{Pr}\left(v_{s}=v_{s}^{k}, v_{w}=v_{w}^{k}\right)=p_{k} \quad \text { for } \quad k=1, \ldots, K
$$

with $p_{1}+\ldots+p_{K}=1$. Dependence between the different unobservable heterogeneity terms is allowed in this specification for $K \geq 2$. The degree of flexibility increases for larger values of $K$. We normalize the model by not including an intercept in the vector of observed characteristics $x$ instead of restricting the locations of the mass points.

It is straightforward to derive the likelihood contributions from the specifications of the different hazard rates. We do not have any initial conditions problems since we use a flow sample of houses entering the market. The right-censoring in the data is exogenous, and is, therefore, solved in a straightforward manner. In particular, let $c_{s}$ equal one if a house is observed to be sold, $c_{w}$ is one if the destination state was withdrawal. If $i=1, \ldots, n$ denote the observations, then the loglikelihood function equals

$$
\begin{array}{r}
\log \ell=\sum_{i=1}^{n} \log \left\{\int_{v_{s}} \int_{v_{w}} \theta_{s}\left(t_{i} \mid x_{i}, \tau_{0, i}, v_{s}\right)^{c_{s, i}} \theta_{w}\left(t_{i} \mid x_{i}, \tau_{0, i}, v_{w}\right)^{c_{w, i}}\right. \\
\exp \left(-\int_{0}^{t_{i}} \theta_{s}\left(z \mid x_{i}, \tau_{0, i}, v_{s}\right)+\theta_{w}\left(z \mid x_{i}, \tau_{0, i}, v_{w}\right) d z\right) \\
\left.d G\left(v_{s}, v_{w}\right)\right\}
\end{array}
$$

If the house was still on the market at the end of the observation period $\left(c_{s}=c_{w}=0\right)$, then $t$ equals the duration until right-censoring.

We perform a number of sensitivity analyses. First, we estimate the model with independent hazard rates of sale and withdrawal. Second, we include the Haurin (1988) atypicallity measure in the set of observed characteristics to see if this changes the duration dependence. Third, we exclude ten percent of the most atypical houses measured along the Haurin (1988) atypicallity measure to see if the results are caused by atypical houses. Last, we want to measure the direct effect of time-on-the-market on the transaction price. We model the transaction price and the hazard of sale and withdrawal simultaneously 
since time-on-the-market and the transaction price are endogenous. We use a hazard rate model for the transaction prices $\mathrm{p}$, with the density function

$$
f_{t}\left(p \mid t, \tau_{0}, x, v_{t}\right)=\theta_{t}\left(p \mid t, \tau_{0}, x, v_{t}\right) \exp \left(-\int_{0}^{p} \theta_{t}\left(s \mid t, \tau_{0}, x, v_{t}\right) d s\right)
$$

with

$$
\theta_{t}\left(p \mid t, \tau_{0}, x, v_{t}\right)=\lambda_{t}(p) \psi_{t}\left(\tau_{0}+t\right) \exp \left(x^{\prime} \beta_{t}+\delta_{t} \cdot t+v_{t}\right)
$$

where $\psi_{t}\left(\tau_{0}+t\right)$ denotes calendar-time effects at the moment of selling the house, and $t$ is the time the house was on the market before being sold. The unobserved heterogeneity term $v_{t}$ can be correlated to the unobserved heterogeneity terms in the selling and withdrawing hazard to account for endogeneity. The parameter of interest is the direct effect of $\delta_{t}$ capturing the effect of time on the market on the transaction price. In using hazard rates models for transaction prices we follow Donald, Green and Paarsch (2000) who implement a hazard-based estimator of wage, earnings, and income densities in the presence of covariates. The results of these sensitivity analyses will be discussed in Subsection 5.2.

\section{The Data}

Our data contains all houses and apartments offered for sale through all real estate brokers associated to the Dutch NVM (Dutch Association of Real Estate Brokers and Real Estate Experts) between January 1985 and December 2007. The Dutch NVM has a market share in the Dutch brokerage market for owner occupied homes of about $70 \%$.

For each dwelling we observe the exact date when it was put on the market, and the initial list price. We also observe the exact date at which the dwelling was sold or was taken off the market. About $10 \%$ of all houses put up for sale are withdrawn from the market. If it was still on the market on January 1, 2008, the time on the market is exogenously right censored.

For each dwelling, we observe a rich set of characteristics. There is information on the type of dwelling (12 types), the construction period ( 5 periods), 


\begin{tabular}{lr} 
Table 1: Some Characteristics of the Data Set \\
\hline \hline Number of observations & $1,820,022$ \\
Number of sales & $1,567,591$ \\
Number of withdrawals & 174,004 \\
Number of right-censored & 78,427 \\
& \\
Average list price & $€ 200,802$ \\
Average selling price & $€ 179,474$ \\
& \\
Average time-till-sale & 87 days \\
Average time-till-withdrawal & 200 days \\
\hline \hline
\end{tabular}

Note.-The sample covers 1985-2007. Time on the market is right-censored for houses which were still on the market on January 1, 2008.

parking facility (4 types), garden location (9 types), and region (76 regions). ${ }^{2}$ The data also include several size characteristics such as the floorsize, lotsize (in square meters), and the number of rooms in the dwelling. Furthermore, we observe whether the dwelling is well isolated, type of heating system (3 types), location next to a quiet road, possible groundlease, presence of an elevator in the apartment building, and two variables measuring inside and outside quality on a discrete scale from 1 to 9 . These quality measures are determined by the real estate broker selling the dwelling.

Table 1 presents some details of the data. Further characteristics of the data are provided in appendix 10. In total our data contain 1,820,022 dwellings put on the market. For 1,567,591 dwellings we observe a sale, 174,004 dwellings were taken off the market, and 78,427 dwellings were still on the market at the end of the observation period. On average, the initial list price is $€ 200,802$ (although the average initial list price for houses which did sell was substantially lower at $€ 188,559)$, and the average selling price is $€ 179,474$. About $86 \%$ of the houses are sold below the list price. $^{3}$

\footnotetext{
${ }^{2}$ Within a NVM region $80 \%$ of the families changing house stay within the region.

${ }^{3}$ The list price premium is the difference between the log of the initial list price of the dwelling and the predicted log value of the initial list price of the dwelling. The predicted $\log$ value of the list price is based on standard loglinear regressions separately performed for each year (e.g. Rosen 1974). The R-squared for these regressions are on average $79.1 \%$ and range between between $77.0 \%$ and $80.9 \%$. This approach is identical to that in Anglin, Rutherford and Springer (2003), and Merlo and Ortalo-Magné (2004). The
} 


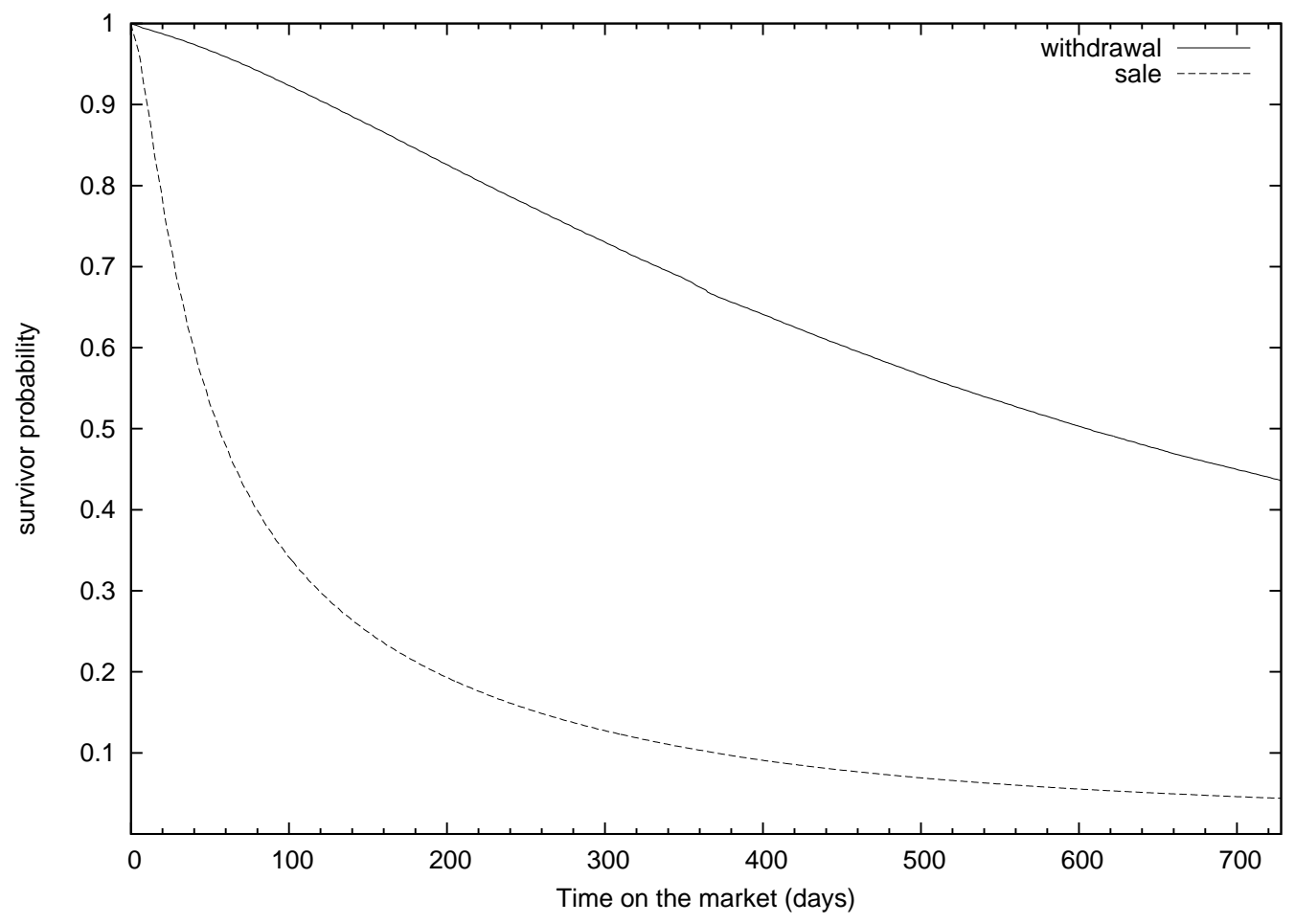

Figure 1: Kaplan-Meier estimates for the survivor function to selling the house and withdrawal.

Figure 1 shows the Kaplan-Meier estimates for the survival function for selling the house and withdrawing from the market (without sale). The survivor function is the probability that a house will stay on the market up till time $t$ (see e.g. Lancaster 1990). When estimating the survivor function for selling the market, withdrawing is considered to be exogenous, and vice versa. This also implies that the probability that a house is still on the market after some duration is the product of the survivor to selling the house and the survivor for withdrawal. If no houses would have been withdrawn before, about $50 \%$ of the houses is sold after 56 days. Withdrawal is a much slower process, it takes 619 days before the probability of withdrawn reached 0.5 .

variable gives us a measure of overpricing or underpricing of the dwelling based on what would be a "normal" list price for the dwelling based on observed characteristics. The estimated coefficients for the year 2007 are presented in appendix 10. 


\section{Estimation Results}

\subsection{Parameter Estimates}

We discuss the results of our empirical analyses in this section. The parameter estimates of the baseline model will be discussed first. The next subsection will discuss the results of the sensitivity analyses.

For the piecewise constant duration dependence we choose the following intervals: 0-30 days, 31-60 days, 61-120 days, 121-180 days, 181-270 days, 271-360 days, 361-720 days, and beyond 720 days. However, in the hazard to withdrawing we merge the last two intervals to one interval beyond 361 days. We have three mass points $(K=3)$ for the unobserved heterogeneity. The vector of observed characteristics includes 141 variables.

The parameter estimates of our baseline model are presented in table 2 . Further parameter estimates of the baseline model are presented in appendix 10. The main parameters of interest are the $\lambda^{\prime} s$, which represent the duration dependence in the hazard of sale and the hazard of withdrawal. These parameter estimates are also presented in figure 2 with their 95 percent confidence bounds.

Note that the hazard rate in the 31-60 day interval is only slightly different (2.3\% higher) from to the 0-30 day interval. After 60 days the hazard rate of sale starts to decline as a function of time on the market. This gradual monotonic decline is consistent with a housing market characterized by asymmetric information where buyers perceive time-on-the-market as a quality signal as in Taylor (1999). The hazard rate of sale is $(\exp (-0.175)-1) \times 100 \%=-16 \%$ lower in the 61-120 day interval compared to the 0-30 day interval. The rather constant hazard rate of sale in the first 60 days combined with the sharp decrease after 60 days is in line with the stock-flow interpretation of Coles and Smith (1998). The current stock of buyers has rejected the house in the first 60 days after which the seller can only match the house with the flow of new buyers entering the market. The stigmatization effect seems to be quite substantial, for example, in the 361-720 day interval the hazard rate of sale is $(\exp (-0.574)-1) \times 100 \%=-44 \%$ lower compared to the $0-30$ day interval.

There is also substantial duration dependence in the hazard rate of with- 
drawal. The hazard rate of withdrawal is monotonically increasing with time-on-the-market. This paper is the first showing empirical evidence in favor of positive duration dependence in the rate of withdrawal. The result is consistent with stigmatized sellers deciding to withdraw their house from the market after spending a long time-on-the-market. The seller prefers a withdrawal over accepting a bid below his reservation price or keeping the house on the market and seeing the probability of sale decline even further with time.

The list-price premium has been included in the set of explanatory variables. The list-price premium is defined as the list-price of the house compared to a hedonic estimate for the list price of the house. A positive listprice premium thus implies that the house is priced high compared to similar houses in the market. We will not give a strong causal interpretation to the covariate effect of the list-price premium on time-on-the-market since some unobservables such as the thinness of a submarket (see e.g. Lazear 1986) can also affect the list-price premium. However, the estimation results are consistent with Lazear (1986) and theories that state that the list price is positively related to the reservation price (e.g. Albrecht, Gautier and Vroman 2009). Houses with a higher list price premium have a lower probability of sale.

The unobserved heterogeneity distribution shows three mass points. Most probability mass (58\%) is located at houses which have a low rate of sale and a low rate of withdrawal. These might for example be sellers who plan to move to a bigger house in the same area and have not purchased a new house yet. They can afford a long time-on-the-market due to a lack of time pressure. The second mass point (39\% probability mass) describes houses which have both a high rate of sale and withdrawal. The third mass point (4\% probability mass) describes houses with a high rate of sale and low rate of withdrawal. These might be houses of which the seller has already bought a new house which causes the seller to set a lower reservation price. The main conclusion is that there are relevant unobserved characteristics which causes dependency between the two hazards. 
Table 2: Estimation Results of the Baseline Model

\begin{tabular}{|c|c|c|c|c|}
\hline \multirow[b]{2}{*}{ Duration dependence } & \multicolumn{2}{|c|}{ Sale Hazard $\theta_{s}$} & \multicolumn{2}{|c|}{$\overline{\text { Exit Hazard } \theta_{w}}$} \\
\hline & & & & \\
\hline$\lambda_{0}(0-30$ days $)$ & 0 & & 0 & \\
\hline$\lambda_{1}$ (31-60 days $)$ & 0.023 & $(0.007)$ & 0.127 & $(0.030)$ \\
\hline$\lambda_{2}$ (61-120 days) & -0.175 & $(0.008)$ & 0.449 & $(0.029)$ \\
\hline$\lambda_{3}(121-180$ days $)$ & -0.347 & $(0.011)$ & 0.651 & $(0.035)$ \\
\hline$\lambda_{4}(181-270$ days $)$ & -0.419 & $(0.013)$ & 0.874 & $(0.039)$ \\
\hline$\lambda_{5}(271-360$ days $)$ & -0.471 & $(0.018)$ & 1.034 & $(0.048)$ \\
\hline$\lambda_{6}(361-720$ days $)$ & -0.574 & $(0.021)$ & 1.290 & $(0.057)$ \\
\hline$\lambda_{7}(>720$ days $)$ & -0.720 & $(0.045)$ & $\ldots$ & \\
\hline List price premium & -0.694 & $(0.014)$ & 0.005 & $(0.043)$ \\
\hline \multicolumn{5}{|c|}{ Unobserved heterogeneity } \\
\hline$v_{1}$ & -6.151 & $(0.398)$ & -8.314 & $(1.057)$ \\
\hline$v_{2}$ & -4.804 & $(0.394)$ & -7.078 & $(1.055)$ \\
\hline$v_{3}$ & -4.740 & $(0.395)$ & -8.706 & $(1.054)$ \\
\hline$p_{1}$ & 0.577 & $(0.044)$ & & \\
\hline$p_{2}$ & 0.387 & $(0.045)$ & & \\
\hline$p_{3}$ & 0.036 & $(0.004)$ & & \\
\hline Additional controls & \multicolumn{2}{|c|}{ Yes } & \multicolumn{2}{|c|}{ Yes } \\
\hline Log likelihood & \multicolumn{4}{|c|}{$-10,084,610.67$} \\
\hline Observations & \multicolumn{4}{|c|}{$1,820,022$} \\
\hline
\end{tabular}

Note.-List-price premium is the difference between the log of the initial list price of the house and the predicted log value of the initial list price of the house. The predicted $\log$ value of the list price is based on a log-linear hedonic regression. Additional controls are for number of rooms, $\log$ (lotsize), $\log$ (lotsize) squared, $\log$ (floorsize), $\log$ (floorsize) squared, construction period, type of house (or type of apartment), presence of a lift in the apartment building, parking facility, garden location, isolation, location to busy roads, groundlease, inside and outside quality of the house, and regions. Standard errors are in parentheses. 


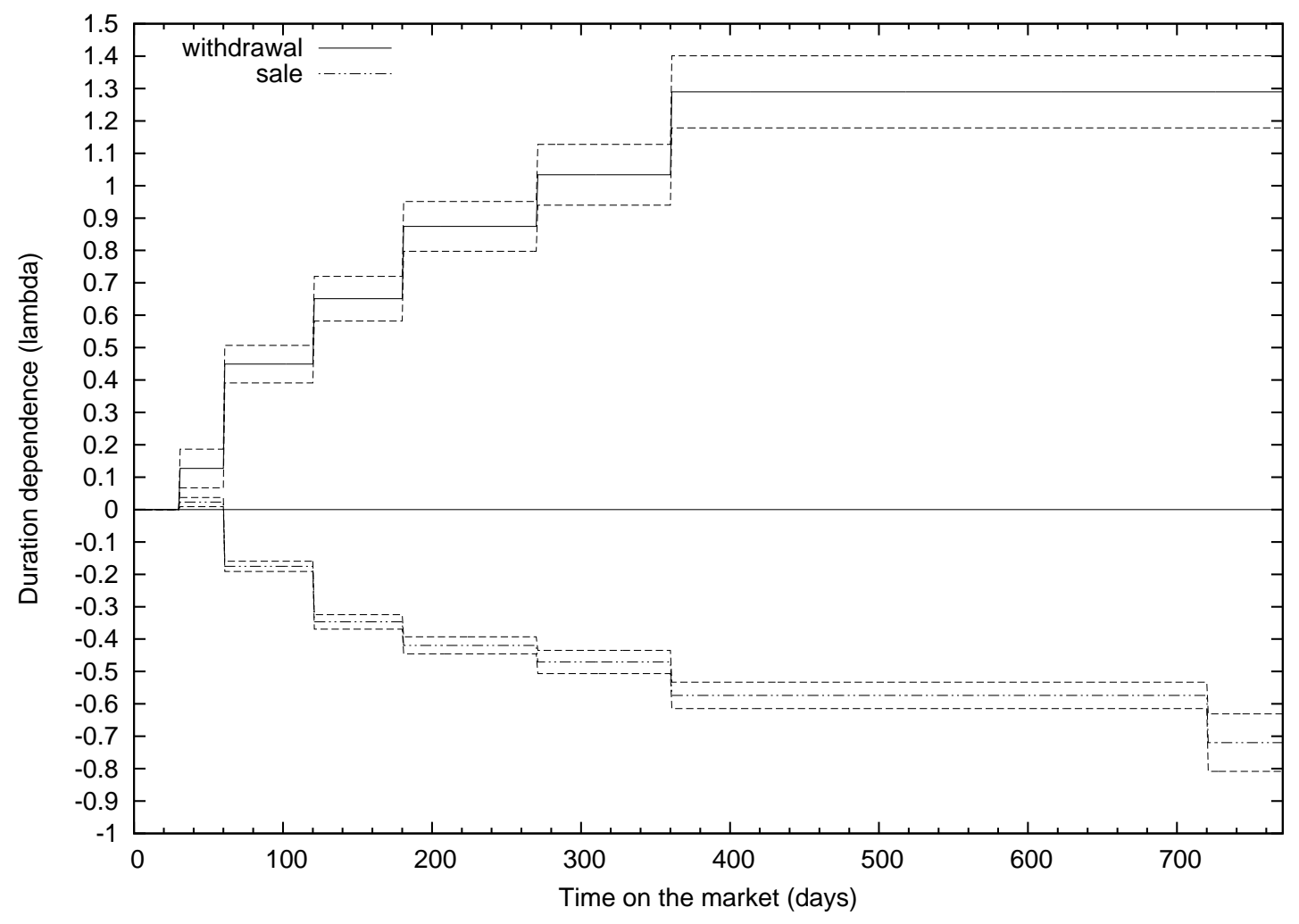

Figure 2: The parameters $\lambda_{s, 0}$ and $\lambda_{s, 0}$ for the first duration interval are normalized to zero. The duration dependence is of the transition rate from market to sale and from market to withdrawal. The figure also presents the 95 percent confidence bounds.

\section{$5.2 \quad$ Sensitivity Analyses}

In this subsection we examine the robustness of our parameter estimates with respect to the model specification. We provide a number of sensitivity analyses and mainly focus on the duration dependence in the hazard rates of sale and withdrawal.

The first sensitivity analysis considers the effects on the parameter estimates of the model when the hazard rates of sale and withdrawal are falsely assumed to be independent of each other. Independence implies that the unobserved heterogeneity components $v_{s}$ and $v_{w}$ are independent. From the top plane in Table 3 it can be seen that not allowing for dependency between 
the hazard rates changes the estimated effects of the duration dependence. The hazard of sale is slightly higher in the first 270 days on the market and lower after that compared to the baseline model. Furthermore, the hazard of withdrawal is higher in all intervals compared to the baseline model, especially the later intervals. The implication is that not allowing for dependence between the hazard rates overstates the stigma effect.

The second sensitivity analysis considers the effect of atypical houses on our results. Haurin (1988) considers how atypical a house is compared to the houses in its region. Summary statistics of the Haurin atypicallity variable are given in appendix 8. First, including the Haurin (1998) atypicallity measure in our set of independent variables does not alter the parameter estimates of the duration dependence terms. Second, we re-estimate the baseline model after removing $10 \%$ of the most atypical houses from the data. From the second plane in Table 3 it can be seen that this only slightly alters the parameter estimates. The implication is that the duration dependence is not driven by atypical houses but also exists in the market for regular houses.

In the last sensitivity analysis, we measure the effect of time-on-themarket on the transaction price as described in subsection 3.2. The lower panel of table presents the results. Note that jointly modelling the transaction price with the sale and withdrawal hazards hardly changes the duration dependence structure for the sale and withdrawal hazards. At the bottom of table 3 it can be seen that the estimated coefficient for time-on-the-market is positive. This means that the transaction price is decreasing with timeon-the-market. It is important here to distinguish between the information known to the market and the information known to the econometrician. Our database does not include data on changes in reservation prices during the time the house is on the market. Although the reservation price itself will be unobserved to buyers in a housing market with asymmetric information, changes in the reservation price might be signalled to the market by reductions of the list price (e.g. de Wit and van der Klaauw 2010). The relation between time-on-the-market and lower transaction prices might therefore be caused by the direct effect of a reduction in the reservation price after the house has been on the market for some time. The main conclusion is that the duration dependence structure in the hazards of sale and withdrawal are 
hardly changed by jointly modelling the sale and withdrawal hazards with the transaction price. 
Table 3: Sensitivity analyses of the duration dependence.

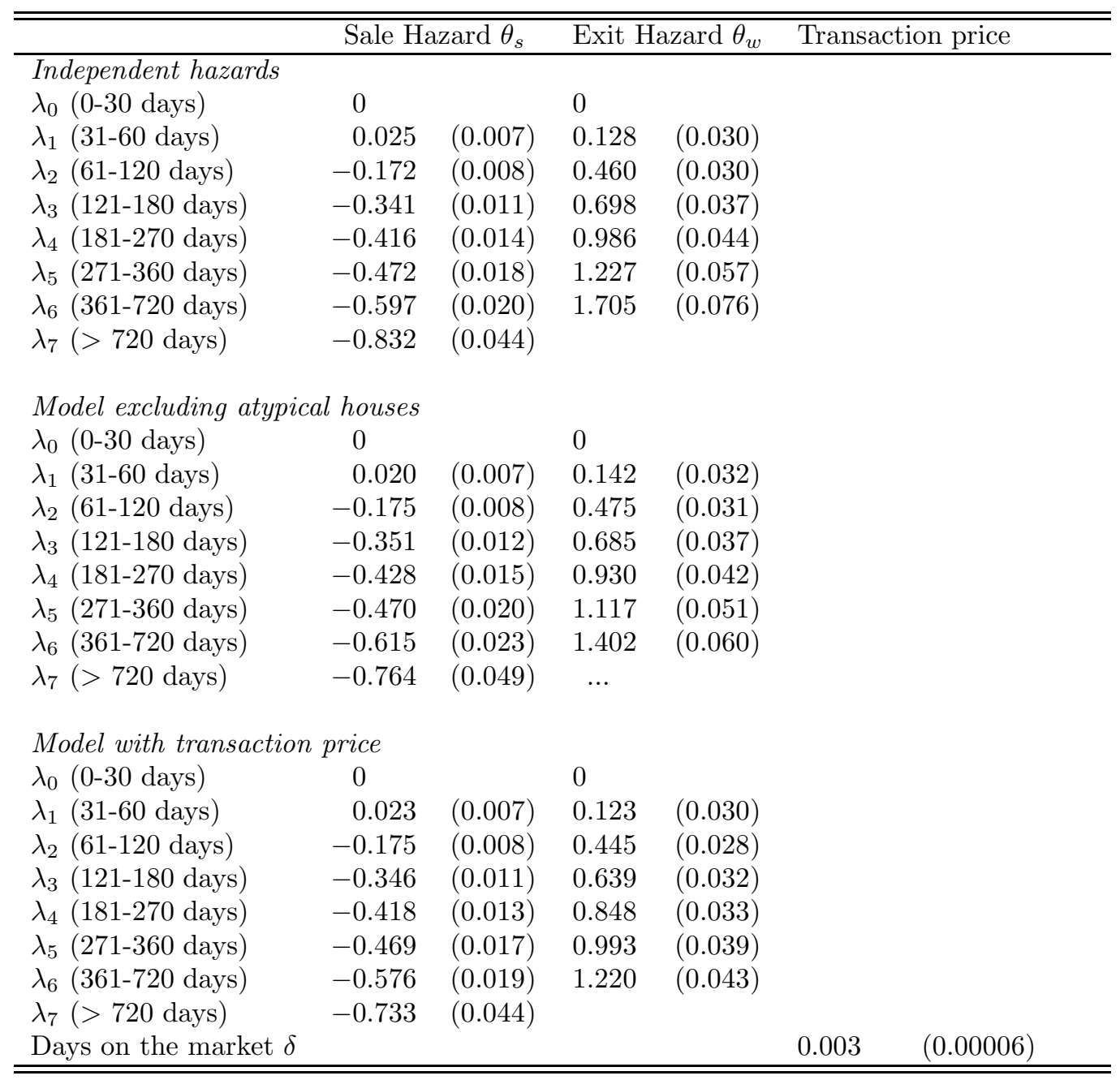

Note.- Similar specification and controls as in the baseline model. The estimated coefficients and standard errors of the model with the atypicallity variable are the same as the baseline model and are therefore not included in the table. Standard errors are in parentheses. Full sets of parameter estimates are available on request. 


\section{Conclusions}

Theoretical models for the sale process in the housing market are scarce. In this paper we test the empirical prediction from Taylor (1999) that the probability of selling a house decreases with the time the house has been for sale on the market. Furthermore, withdrawals from the market are not exogenous to sales (see e.g. Caplin and Leahy 1996). Therefore, we model the hazard rate of sale and the hazard rate of withdrawal simultaneously. Taylor states that houses can become stigmatized after they have remained on the market for a long time. Owners of stigmatized houses might prefer a withdrawal of their house from the market over seeing their house becoming even more stigmatized. Thus, the probability of withdrawal can be expected to be increasing with time-on-the market.

We specified a duration model with competing risks (a sale or withdrawal from the market) and unobserved heterogeneity. We find positive duration dependence in the hazard of sale, meaning that the probability of a sale decreases with time-on-the-market. Furthermore, we also find that the probability of withdrawal increases with time-on-the-market. This is the first paper finding evidence for positive duration dependence in the hazard of withdrawal. 


\section{References}

Albrecht, J., P. Gautier and S. Vroman (2009), Directed Search in the Housing Market, Tinbergen Institute, Working Paper.

Anglin, P.M., R. Rutherford and T.M. Springer (2003), The Trade-off between the Selling Price of Residential Properties and Time-on -the-Market: The Impact of Price Setting, Journal of Real Estate Finance and Economics 26(1), 95-111.

Ball, M. (2009), RICS European Housing Review 2009, RICS, London.

Caplin, A., and J. Leahy (1996), Trading Costs, Price, and Volume in Asset Markets, The American Economic Review 86(2), 192-196.

Coles, M.G. and E. Smith (1998), Marketplaces and Matching, International Economic Review 39(1), 239-254.

Conijn, J. and F. Schilder (2009), How Housing Associations lose their value: the value gap in the Netherlands, ERES Conference Paper, Stockholm.

De Wit, E.R. and van der Klaauw (2010), Asymmetric Information and List Price Reductions in the Housing Market, Tinbergen Institute, Working Paper.

Donald, S.G., D.A. Green and H.J. Paarsch (2000), Differences in Wage Distributions between Canada and the United States: An Application of a Flexible Estimator of Distribution Functions in the Presence of Covariates, The Review of Economic Studies 67(4), 609-633

Haurin, D. (1988), The Duration of Marketing Time of Residential Housing, AREUEA Journal 60(4), 396-410.

Heckman, J.J. and B.E. Honoré (1989), The Identifiability of the Competing Risks Model, Biometrica 76(1), 325-330.

Heckman, J. and B. Singer (1984), A Method for Minimizing the Impact of Distributional Assumptions in Econometric Models for Duration Data, Econometrica 52(2), 271-320.

Huang, J. and R.B. Palmquist (2001), Environmental Conditions, Reservation Prices, and Time on the Market for Housing, Journal of Real Estate Finance and Economics 22(2), 203-219. 
Koning, M.A., R. Saitua and J. Ebregt (2006), Woningmarkteffecten van aanpassing fiscale behandeling eigen woning, CPB-Document (128), CPB, The Hague.

Lancaster, T. (1990), The Econometric Analysis of Transition Data, Cambridge University Press, Cambridge.

Lazear, E.P. (1986), Retail Pricing and Clearance Sales, The American Economic Review 76(1), 14-32.

Merlo, A. and F. Ortalo-Magné (2004), Bargaining over residential real estate: evidence from England, Journal of Urban Economics 56(2), 192-216.

Olsen, E.O. (1969), A Competitive Theory of the Housing Market, The American Economic Review 59(4), 612-622.

OTB (2003), Homebuyers in Profile 1995-2002, OTB Research Institute for Housing, Urban and Mobility Studies.

Pryce, G. and K. Gibb (2006), Submarket Dynamics of Time to Sale, Real Estate Economics 34(3), 377-415.

Romijn, G. and P. Besseling (2008), Economische effecten van regulering en subsidiring van de huurwoningmarkt, CPB-Document (168), CPB, The Hague.

Rosen, S. (1974), Hedonic Prices and Implicit Markets: Product Differentiation in Pure Competition, The Journal of Political Economy 82(1), 34-55.

Swank, J., J. Kakes and A. Tieman (2002), The housing ladder, taxation, and borrowing constraints, DNB Working Paper 2002(9), De Nederlandsche Bank, Amsterdam.

Taylor, C.R. (1999), Time-on-the-Market as a Sign of Quality, The Review of Economic Studies 66(3), 555-578.

Van Ewijk, C. and H. ter Rele (2008), Macro-economische verkenning van de huizenmarkt, in F.J.H. Don (ed.), Agenda voor de woningmarkt, Koninklijke Vereniging voor de Staathuishoudkunde, Preadviezen 2008.

Vermeulen, W., and J. Rouwendal (2007), Housing supply in the Netherlands, CPB-Document (87), CPB, The Hague. 
Zuehlke, T.W. (1987), Duration Dependence in the Housing Market, The Review of Economics and Statistics 69(4), 701-709.

\section{Appendix: Hedonic Regression}

Table 4: List Price Hedonic Regression for 2007 (I)

\begin{tabular}{|c|c|c|}
\hline Constant & 7.752 & $(0.013)$ \\
\hline \multicolumn{3}{|l|}{ Seize Characteristics } \\
\hline Number of Rooms & 0.011 & $(0.001)$ \\
\hline Log(lotsize) & -0.046 & $(0.001)$ \\
\hline $\log (\operatorname{lotsize})^{2}$ & 0.010 & $(0.000)$ \\
\hline $\log$ (floorsize) & 0.002 & $(0.030)$ \\
\hline $\log (\text { floorsize })^{2}$ & 0.087 & $(0.003)$ \\
\hline \multicolumn{3}{|l|}{ Construction Period (1991-2000 is base) } \\
\hline Before 1905 & 0.012 & $(0.027)$ \\
\hline 1906-1944 & -0.038 & $(0.002)$ \\
\hline 1945-1990 & -0.116 & $(0.001)$ \\
\hline After 2001 & 0.001 & $(0.002)$ \\
\hline \multicolumn{3}{|l|}{ Type of House (Terraced House is base) } \\
\hline Back-to-Back Housing & 0.098 & $(0.004)$ \\
\hline CornerHouse & 0.034 & $(0.002)$ \\
\hline Semi-Detached & 0.127 & $(0.002)$ \\
\hline Detached & 0.318 & $(0.002)$ \\
\hline \multicolumn{3}{|l|}{ Type of Apartment } \\
\hline Split-Level (Ground Floor) & 0.304 & $(0.004)$ \\
\hline Split-Level (Upper Floor) & 0.214 & $(0.004)$ \\
\hline Maisonette & 0.154 & $(0.005)$ \\
\hline Porch Flat & 0.210 & $(0.004)$ \\
\hline Galary Glat & 0.164 & $(0.004)$ \\
\hline Elderly Flat & -0.113 & $(0.017)$ \\
\hline Split-Level (Ground and Upper Floor) & 0.291 & $(0.012)$ \\
\hline
\end{tabular}

Note.- The dependent variable is $\log ($ list price). Standard errors are in parentheses. 
Table 5: List Price Hedonic Regression for 2007 (II)

Parking (No Parking is base)

\begin{tabular}{|c|c|c|}
\hline Parking & 0.063 & $(0.002)$ \\
\hline Garage & 0.109 & $(0.002)$ \\
\hline Carport & 0.117 & $(0.003)$ \\
\hline \multicolumn{3}{|c|}{ Garden (South-East is base) } \\
\hline No Garden & 0.026 & $(0.002)$ \\
\hline North Side & -0.011 & $(0.003)$ \\
\hline North-East Side & -0.007 & $(0.003)$ \\
\hline East Side & -0.012 & $(0.003)$ \\
\hline South Side & 0.000 & $(0.003)$ \\
\hline South-West Side & 0.009 & $(0.003)$ \\
\hline West Side & -0.009 & $(0.003)$ \\
\hline North-West Side & 0.002 & $(0.003)$ \\
\hline \multicolumn{3}{|l|}{ Miscellaneous } \\
\hline Lift & 0.063 & $(0.002)$ \\
\hline Well Isolated & -0.017 & $(0.002)$ \\
\hline Located to quiet road & 0.005 & $(0.001)$ \\
\hline Located to busy road & -0.009 & $(0.003)$ \\
\hline Groundlease & -0.113 & $(0.002)$ \\
\hline Quality Interior & 0.038 & $(0.001)$ \\
\hline Quality Exterior & 0.011 & $(0.001)$ \\
\hline \multicolumn{3}{|c|}{ Month Dummies (January is Base) } \\
\hline February & 0.006 & $(0.003)$ \\
\hline March & 0.016 & $(0.003)$ \\
\hline April & 0.025 & $(0.003)$ \\
\hline May & 0.035 & $(0.003)$ \\
\hline June & 0.036 & $(0.003)$ \\
\hline July & 0.036 & $(0.003)$ \\
\hline August & 0.036 & $(0.003)$ \\
\hline September & 0.048 & $(0.003)$ \\
\hline October & 0.047 & $(0.003)$ \\
\hline November & 0.050 & $(0.003)$ \\
\hline December & 0.047 & $(0.003)$ \\
\hline Additional Controls & Yes & \\
\hline $\mathrm{R}^{2}$ Adjusted & $80.4 \%$ & \\
\hline Number of observations & 176,589 & \\
\hline
\end{tabular}

Note.-The dependent variable is $\log$ (list price). Additional controls are for region. There are 76 regions. These regions are defined by the Dutch NVM as an area wherein $80 \%$ of the people who move stay within the region. Standard errors are in parentheses. 


\section{Appendix: Haurin Atypicallity Variable}

This appendix provides summary statistics for the Haurin(1988) atypicallity variable. The controls used in the hedonic regression to construct the atypicallity variable are number of rooms, $\log (\operatorname{lotsize}), \log (\operatorname{lotsize})$ squared, $\log$ (floorsize), $\log$ (floorsize) squared, construction period, type of house (or type of apartment), presence of a lift in the apartment building, parking facility, garden location, isolation, location to busy roads, groundlease, inside and outside quality of the house, and the NVM broker regions.

Table 6: Descriptive Statistics

\begin{tabular}{lcccc}
\hline \hline & & & & \\
& Mean & St.Dev. & Min. & Max. \\
\hline Haurin atypicallity & 0.015 & 0.085 & -0.050 & 1.011 \\
& & & & \\
\hline \hline
\end{tabular}




\section{Appendix: Summary Statistics}

Table 7: Descriptive Statistics

\begin{tabular}{lcccc}
\hline \hline & & & & \\
& Mean & St.Dev. & Min. & Max. \\
\hline List-price premium & 0.000 & 0.187 & -0.487 & 0.461 \\
Number of rooms & 4.423 & 1.342 & 1.000 & 20.000 \\
Log(lotsize) & 4.164 & 2.442 & 0.000 & 13.816 \\
Log(lotsize) & 23.302 & 16.339 & 0.000 & 190.868 \\
Log(floorsize) & 4.753 & 0.340 & 3.714 & 6.290 \\
Log(floorsize) & 22.706 & 3.259 & 13.791 & 39.561 \\
Quality Interior & 7.081 & 1.159 & 1.000 & 9.000 \\
Quality Exterior & 7.097 & 1.065 & 1.000 & 9.000 \\
& & & & \\
\hline \hline
\end{tabular}

Note.-List-price premium is the difference between the log of the initial list price of the house and the predicted log value of the initial list price of the house. The predicted $\log$ value of the list price is based on a log-linear hedonic regression. Additional controls are for number of rooms, $\log$ (lotsize), $\log$ (lotsize) squared, $\log$ (floorsize), $\log$ (floorsize) squared, construction period, type of house (or type of apartment), presence of a lift in the apartment building, parking facility, garden location, isolation, location to busy roads, groundlease, inside and outside quality of the house, and regions. 
Table 8: Frequencies (I)

\begin{tabular}{|c|c|}
\hline & Frequency \\
\hline \multicolumn{2}{|l|}{ Construction Period } \\
\hline Before 1905 & $0.725 \%$ \\
\hline 1906-1944 & $21.537 \%$ \\
\hline 1945-1990 & $61.328 \%$ \\
\hline $1991-2000$ & $13.718 \%$ \\
\hline After 2001 & $2.693 \%$ \\
\hline \multicolumn{2}{|l|}{ Type of House } \\
\hline Terraced House & $30.219 \%$ \\
\hline Back-to-Back Housing & $2.193 \%$ \\
\hline Cornerhouse & $13.439 \%$ \\
\hline Semi-Detached & $14.830 \%$ \\
\hline Detached & $14.578 \%$ \\
\hline \multicolumn{2}{|l|}{ Type of Apartment } \\
\hline Split-Level (Ground Floor) & $3.033 \%$ \\
\hline Split-Level (Upper Floor) & $5.563 \%$ \\
\hline Maisonette & $2.074 \%$ \\
\hline Porch Flat & $7.273 \%$ \\
\hline Galary Flat & $6.358 \%$ \\
\hline Elderly Flat & $0.156 \%$ \\
\hline Split-Level (Ground and Upper Floor) & $0.283 \%$ \\
\hline \multicolumn{2}{|l|}{ Parking } \\
\hline Parking & $4.243 \%$ \\
\hline No Parking & $56.609 \%$ \\
\hline Garage & $28.723 \%$ \\
\hline Carport & $3.852 \%$ \\
\hline \multicolumn{2}{|l|}{ Garden } \\
\hline No Garden & $34.257 \%$ \\
\hline North Side & $6.177 \%$ \\
\hline North-East Side & $4.404 \%$ \\
\hline East Side & $8.330 \%$ \\
\hline South-East Side & $7.632 \%$ \\
\hline South Side & $14.870 \%$ \\
\hline South-West Side & $9.899 \%$ \\
\hline West Side & $9.709 \%$ \\
\hline North-West Side & $4.722 \%$ \\
\hline
\end{tabular}


Table 9: Frequencies (II)

\begin{tabular}{lc}
\hline \hline & Frequency \\
\hline Miscellaneous & \\
Lift & $7.033 \%$ \\
Well Isolated & $77.620 \%$ \\
Located to quiet road & $28.523 \%$ \\
Located to busy road & $3.135 \%$ \\
Groundlease & $5.415 \%$ \\
& \\
Province & \\
Groningen & $4.253 \%$ \\
Friesland & $3.490 \%$ \\
Drenthe & $3.767 \%$ \\
Overijssel & $6.769 \%$ \\
Flevoland & $2.524 \%$ \\
Gelderland & $13.315 \%$ \\
Utrecht & $9.282 \%$ \\
Noord-Holland & $18.434 \%$ \\
Zuid-Holland & $20.450 \%$ \\
Zeeland & $1.422 \%$ \\
Noord-Brabant & $13.658 \%$ \\
Limburg & $2.635 \%$ \\
& \\
\hline \hline
\end{tabular}




\section{Appendix: Further Estimation Results of the Baseline Model}

This appendix provides further estimation results for the coefficients of the covariates of the baseline model.

Table 10: Further Estimation Results of the Baseline Model (I)

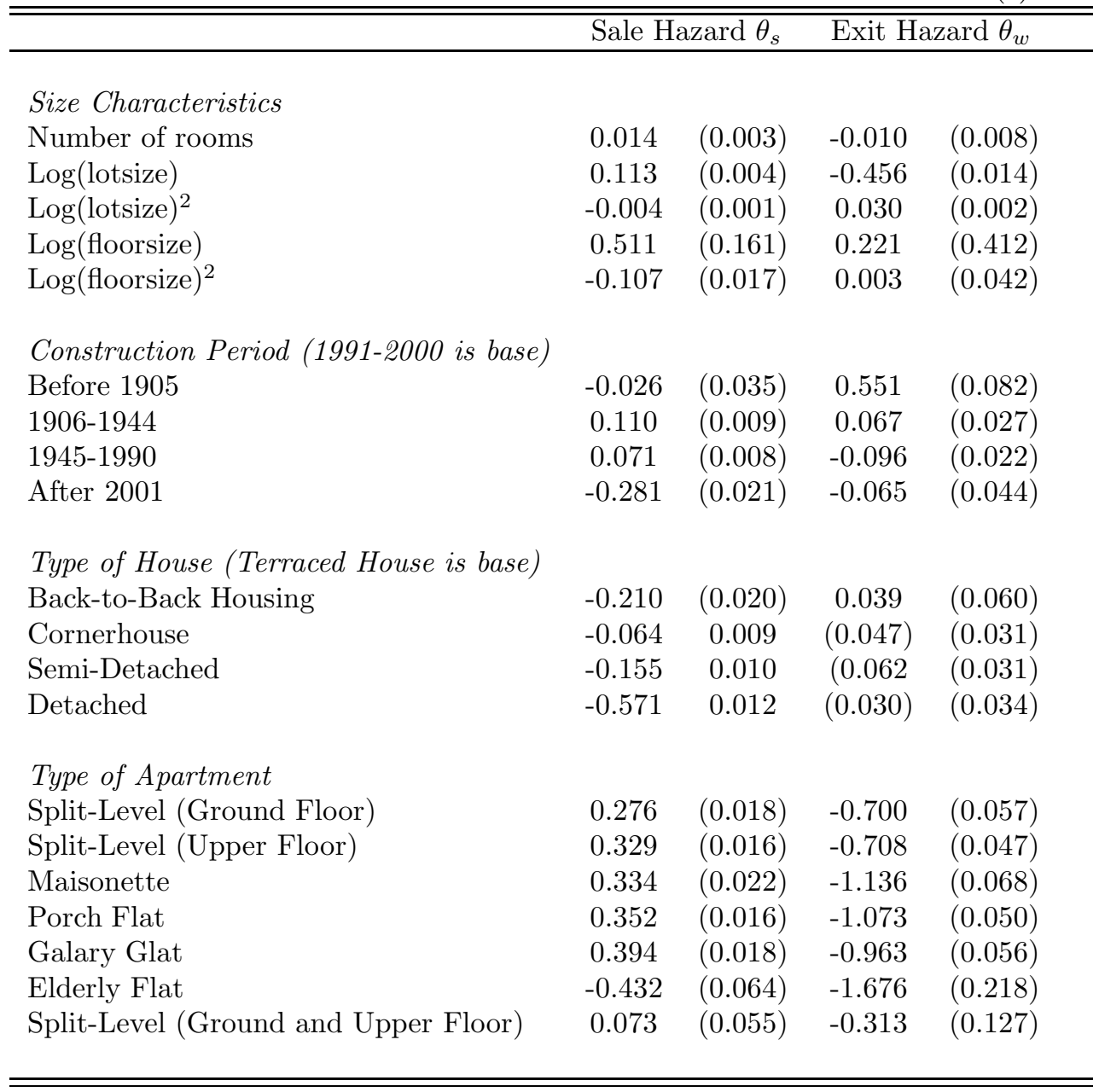

Note.-Standard errors are in parentheses. 
Table 11: Further Estimation Results of the Baseline Model (II)

\begin{tabular}{|c|c|c|c|c|}
\hline & \multicolumn{2}{|c|}{ Sale Hazard $\theta_{s}$} & \multicolumn{2}{|c|}{ Exit Hazard $\theta_{w}$} \\
\hline \multicolumn{5}{|c|}{ Parking (No Parking is base) } \\
\hline Parking & -0.116 & $(0.014)$ & -0.060 & $(0.039)$ \\
\hline Garage & -0.075 & $(0.008)$ & -0.014 & $(0.023)$ \\
\hline Carport & -0.118 & $(0.015)$ & -0.045 & $(0.041)$ \\
\hline \multicolumn{5}{|c|}{ Garden (South-East Side is base) } \\
\hline No Garden & -0.130 & $(0.012)$ & 0.051 & $(0.038)$ \\
\hline North Side & -0.037 & $(0.015)$ & 0.020 & $(0.049)$ \\
\hline North-East Side & 0.001 & $(0.016)$ & 0.086 & $(0.053)$ \\
\hline East Side & -0.008 & $(0.014)$ & 0.048 & $(0.046)$ \\
\hline South Side & 0.013 & $(0.012)$ & 0.031 & $(0.040)$ \\
\hline South-West Side & 0.016 & $(0.013)$ & 0.032 & $(0.044)$ \\
\hline West Side & 0.002 & $(0.013)$ & 0.045 & $(0.044)$ \\
\hline North-West Side & -0.007 & $(0.016)$ & 0.006 & $(0.053)$ \\
\hline \multicolumn{5}{|l|}{ Miscellaneous } \\
\hline Lift & -0.122 & $(0.014)$ & -0.151 & $(0.039)$ \\
\hline Well Isolated & 0.003 & $(0.007)$ & -0.107 & $(0.021)$ \\
\hline Located to quiet road & 0.034 & $(0.007)$ & 0.002 & $(0.020)$ \\
\hline Located to busy road & -0.084 & $(0.016)$ & 0.026 & $(0.044)$ \\
\hline Groundlease & -0.040 & 0.013 & $(0.008)$ & $(0.038)$ \\
\hline Quality Interior & -0.031 & $(0.004)$ & 0.049 & $(0.012)$ \\
\hline Quality Exterior & -0.006 & $(0.004)$ & -0.003 & $(0.013)$ \\
\hline \multicolumn{5}{|c|}{ Province (Noord-Holland is base) } \\
\hline Groningen & 0.146 & $(0.015)$ & -0.263 & $(0.046)$ \\
\hline Friesland & 0.033 & $(0.008)$ & -0.199 & $(0.025)$ \\
\hline Drenthe & 0.010 & $(0.005)$ & -0.101 & $(0.016)$ \\
\hline Overijssel & 0.001 & $(0.003)$ & -0.106 & $(0.010)$ \\
\hline Flevoland & -0.027 & $(0.004)$ & -0.059 & $(0.010)$ \\
\hline Gelderland & 0.012 & $(0.002)$ & -0.081 & $(0.005)$ \\
\hline Utrecht & 0.024 & $(0.002)$ & -0.034 & $(0.005)$ \\
\hline Zuid-Holland & -0.005 & $(0.001)$ & -0.039 & $(0.003)$ \\
\hline Zeeland & -0.007 & $(0.002)$ & -0.021 & $(0.007)$ \\
\hline Noord-Brabant & 0.013 & $(0.001)$ & -0.032 & $(0.003)$ \\
\hline Limburg & -0.002 & $(0.002)$ & 0.003 & $(0.004)$ \\
\hline
\end{tabular}

Note.-Standard errors are in parentheses. 
Table 12: Further Estimation Results of the Baseline Model (III)

\begin{tabular}{|c|c|c|c|c|}
\hline & \multicolumn{2}{|c|}{ Sale Hazard $\theta_{s}$} & \multicolumn{2}{|c|}{ Exit Hazard $\theta_{w}$} \\
\hline & & & & \\
\hline 1985 Q2 & -0.077 & $(0.092)$ & -0.105 & $(0.328)$ \\
\hline 1985 Q3 & -0.032 & $(0.091)$ & 0.041 & $(0.313)$ \\
\hline $1985 \mathrm{Q} 4$ & -0.032 & $(0.090)$ & -0.005 & $(0.314)$ \\
\hline 1986 Q1 & -0.050 & $(0.090)$ & 0.017 & $(0.313)$ \\
\hline 1986 Q2 & 0.127 & $(0.086)$ & -0.113 & $(0.314)$ \\
\hline 1986 Q3 & 0.151 & $(0.087)$ & -0.199 & $(0.314)$ \\
\hline 1986 Q4 & 0.161 & $(0.088)$ & 0.034 & $(0.310)$ \\
\hline 1987 Q1 & 0.209 & $(0.088)$ & -0.036 & $(0.311)$ \\
\hline 1987 Q2 & 0.217 & $(0.086)$ & -0.174 & $(0.314)$ \\
\hline 1987 Q3 & 0.158 & $(0.088)$ & 0.003 & $(0.310)$ \\
\hline 1987 Q4 & 0.221 & $(0.088)$ & 0.115 & $(0.308)$ \\
\hline 1988 Q1 & 0.345 & $(0.088)$ & 0.022 & $(0.310)$ \\
\hline 1988 Q2 & 0.330 & $(0.086)$ & 0.180 & $(0.309)$ \\
\hline 1988 Q3 & 0.296 & $(0.088)$ & 0.028 & $(0.313)$ \\
\hline 1988 Q4 & 0.309 & $(0.087)$ & -0.073 & $(0.316)$ \\
\hline 1989 Q1 & 0.480 & $(0.086)$ & 0.273 & $(0.311)$ \\
\hline 1989 Q2 & 0.497 & $(0.086)$ & 0.122 & $(0.315)$ \\
\hline 1989 Q3 & 0.350 & $(0.088)$ & 0.023 & $(0.316)$ \\
\hline 1989 Q4 & 0.343 & $(0.088)$ & 0.012 & $(0.315)$ \\
\hline 1990 Q1 & 0.373 & $(0.087)$ & 0.327 & $(0.308)$ \\
\hline 1990 Q2 & 0.286 & $(0.087)$ & -0.030 & $(0.314)$ \\
\hline 1990 Q3 & 0.391 & $(0.087)$ & 0.113 & $(0.312)$ \\
\hline 1990 Q4 & 0.397 & $(0.087)$ & 0.130 & $(0.313)$ \\
\hline 1991 Q1 & 0.362 & $(0.087)$ & -0.059 & $(0.316)$ \\
\hline 1991 Q2 & 0.605 & $(0.085)$ & 0.132 & $(0.312)$ \\
\hline 1991 Q3 & 0.549 & $(0.086)$ & 0.161 & $(0.313)$ \\
\hline 1991 Q4 & 0.522 & $(0.085)$ & 0.102 & $(0.315)$ \\
\hline 1992 Q1 & 0.682 & $(0.085)$ & 0.170 & $(0.315)$ \\
\hline 1992 Q2 & 0.768 & $(0.084)$ & 0.089 & $(0.318)$ \\
\hline 1992 Q3 & 0.778 & $(0.085)$ & 0.323 & $(0.315)$ \\
\hline $1992 \mathrm{Q} 4$ & 0.758 & $(0.084)$ & 0.143 & $(0.322)$ \\
\hline 1993 Q1 & 0.928 & $(0.084)$ & 0.131 & $(0.320)$ \\
\hline 1993 Q2 & 0.920 & $(0.084)$ & 0.449 & $(0.313)$ \\
\hline 1993 Q3 & 0.978 & $(0.084)$ & 0.144 & $(0.321)$ \\
\hline 1993 Q4 & 0.939 & $(0.084)$ & 0.131 & $(0.323)$ \\
\hline 1994 Q1 & 0.952 & $(0.083)$ & 0.323 & $(0.317)$ \\
\hline 1994 Q2 & 0.809 & $(0.084)$ & 0.417 & $(0.314)$ \\
\hline 1994 Q3 & 0.656 & $(0.085)$ & 0.336 & $(0.314)$ \\
\hline 1994 Q4 & 0.697 & $(0.083)$ & 0.143 & $(0.317)$ \\
\hline
\end{tabular}

Note.-Standard errors are in parentheses. 
Table 13: Further Estimation Results of the Baseline Model (IV)

\begin{tabular}{|c|c|c|c|c|}
\hline & \multicolumn{2}{|c|}{ Sale Hazard $\theta_{s}$} & \multicolumn{2}{|c|}{ Exit Hazard $\theta_{w}$} \\
\hline & & & & \\
\hline 1995 Q1 & 0.701 & $(0.083)$ & 0.325 & $(0.313)$ \\
\hline 1995 Q2 & 0.715 & $(0.082)$ & 0.503 & $(0.310)$ \\
\hline 1995 Q3 & 0.713 & $(0.081)$ & 0.126 & $(0.317)$ \\
\hline 1995 Q4 & 0.738 & $(0.081)$ & 0.163 & $(0.316)$ \\
\hline 1996 Q1 & 0.916 & $(0.080)$ & 0.383 & $(0.317)$ \\
\hline 1996 Q2 & 0.844 & $(0.081)$ & 0.781 & $(0.310)$ \\
\hline 1996 Q3 & 0.766 & $(0.081)$ & 0.810 & $(0.310)$ \\
\hline 1996 Q4 & 0.660 & $(0.081)$ & 0.422 & $(0.317)$ \\
\hline 1997 Q1 & 0.806 & $(0.081)$ & 0.682 & $(0.312)$ \\
\hline 1997 Q2 & 0.675 & $(0.080)$ & 0.768 & $(0.307)$ \\
\hline 1997 Q3 & 0.652 & $(0.080)$ & 0.598 & ( 0.309$)$ \\
\hline 1997 Q4 & 0.476 & $(0.080)$ & 1.134 & $(0.303)$ \\
\hline 1998 Q1 & 0.667 & $(0.080)$ & 0.961 & $(0.305)$ \\
\hline 1998 Q2 & 0.643 & $(0.080)$ & 0.690 & $(0.308)$ \\
\hline 1998 Q3 & 0.625 & $(0.080)$ & 0.615 & $(0.309)$ \\
\hline 1998 Q4 & 0.648 & $(0.080)$ & 0.541 & $(0.310)$ \\
\hline 1999 Q1 & 0.829 & $(0.079)$ & 0.724 & $(0.308)$ \\
\hline 1999 Q2 & 0.813 & $(0.079)$ & 0.540 & $(0.311)$ \\
\hline 1999 Q3 & 0.664 & $(0.080)$ & 0.667 & $(0.308)$ \\
\hline 1999 Q4 & 0.484 & $(0.080)$ & 0.756 & $(0.305)$ \\
\hline 2000 Q1 & 0.526 & $(0.080)$ & 0.762 & $(0.304)$ \\
\hline 2000 Q2 & 0.474 & $(0.079)$ & 0.427 & $(0.307)$ \\
\hline 2000 Q3 & 0.463 & $(0.079)$ & 0.656 & $(0.303)$ \\
\hline 2000 Q4 & 0.351 & $(0.079)$ & 0.549 & $(0.304)$ \\
\hline 2001 Q1 & 0.397 & $(0.079)$ & 0.465 & $(0.304)$ \\
\hline $2001 \mathrm{Q} 2$ & 0.360 & $(0.079)$ & 0.574 & $(0.302)$ \\
\hline 2001 Q3 & 0.383 & $(0.079)$ & 0.642 & $(0.302)$ \\
\hline 2001 Q4 & 0.430 & $(0.079)$ & 0.871 & $(0.301)$ \\
\hline 2002 Q1 & 0.376 & $(0.080)$ & 0.468 & $(0.304)$ \\
\hline $2002 \mathrm{Q} 2$ & 0.280 & $(0.079)$ & 0.514 & $(0.302)$ \\
\hline 2002 Q3 & 0.125 & $(0.079)$ & 0.315 & $(0.302)$ \\
\hline $2002 \mathrm{Q} 4$ & -0.020 & $(0.079)$ & 0.360 & $(0.301)$ \\
\hline 2003 Q1 & 0.056 & $(0.079)$ & 0.493 & $(0.299)$ \\
\hline 2003 Q2 & -0.124 & $(0.079)$ & 0.302 & $(0.299)$ \\
\hline 2003 Q3 & -0.280 & $(0.079)$ & 0.193 & $(0.299)$ \\
\hline 2003 Q4 & -0.397 & $(0.079)$ & -0.059 & $(0.299)$ \\
\hline 2004 Q1 & -0.437 & $(0.079)$ & 0.113 & $(0.298)$ \\
\hline $2004 \mathrm{Q} 2$ & -0.319 & $(0.079)$ & 0.122 & $(0.298)$ \\
\hline 2004 Q3 & -0.373 & $(0.079)$ & 0.126 & $(0.298)$ \\
\hline 2004 Q4 & -0.325 & $(0.079)$ & 0.223 & $(0.297)$ \\
\hline
\end{tabular}

Note.-Standard errors are in parentheses. 
Table 14: Further Estimation Results of the Baseline Model (V)

\begin{tabular}{|c|c|c|}
\hline & Sale Hazard $\theta_{s}$ & Exit Hazard $\theta_{w}$ \\
\hline \multicolumn{3}{|l|}{ Calendar Time Dummies (1985Q1 is base) } \\
\hline $2005 \mathrm{Q} 1$ & $(0.079)$ & $(0.297)$ \\
\hline $2005 \mathrm{Q} 2$ & $(0.078)$ & $(0.297)$ \\
\hline 2005 Q3 & $(0.078)$ & $(0.297)$ \\
\hline $2005 \mathrm{Q} 4$ & $(0.078)$ & $(0.297)$ \\
\hline 2006 Q1 & $(0.078)$ & $(0.297)$ \\
\hline $2006 \mathrm{Q} 2$ & $(0.078)$ & $(0.297)$ \\
\hline 2006 Q3 & $(0.079)$ & $(0.297)$ \\
\hline $2006 \mathrm{Q} 4$ & $(0.078)$ & $(0.297)$ \\
\hline 2007 Q1 & $(0.078)$ & $(0.297)$ \\
\hline $2007 \mathrm{Q} 2$ & $(0.078)$ & $(0.297)$ \\
\hline 2007 Q3 & $(0.078)$ & $(0.297)$ \\
\hline 2007 Q4 & $-0.413 \quad(0.079)$ & $0.118 \quad(0.297)$ \\
\hline
\end{tabular}

Note.-Standard errors are in parentheses. 